\title{
Are the underweight more ill than those of acceptable weight or overweight?
}

\author{
Shona Kelly, Jo Leonardi-Bee and Jeanette Lilley \\ University of Nottingham, Nottingham, UK
}

A recent paper has created considerable furore by concluding that those who are underweight or obese are at greater risk of mortality than those of acceptable weight or those who are overweight ${ }^{(1)}$. Critics of the paper have claimed that individuals in the underweight category may have underlying chronic disease, be smokers or that the overweight lead a healthy active lifestyle and carry more muscle mass ${ }^{(2)}$. A review of the literature on the 'underweight' has indicated a dearth of research on the characteristics of individuals in the underweight category, although a 'J'-shaped relationship between BMI and many factors has been noted. This uncertainty makes it difficult to determine whether to include or exclude these individuals when estimating the health and mortality impacts of BMI.

Data on 13343 community-living residents from the 2003 version of the Health Survey for England ${ }^{(3)}$ were used. BMI was categorized using the WHO recommendations ${ }^{(4)}$. Logistic regression models were constructed to compare demographic information, biochemical and anthropometric measurements in the underweight $\left(<18.5 \mathrm{~kg} / \mathrm{m}^{2}\right)$ with those classified as acceptable weight $\left(18.5-24.9 \mathrm{~kg} / \mathrm{m}^{2}\right)$ or overweight $\left(25.0-29.9 \mathrm{~kg} / \mathrm{m}^{2}\right)$.

Univariate analyses showed that compared with the other BMI categories, the underweight were more likely to be young, smokers, abstainers from alcohol and inactive (all $P<0.001$ ). They were also more likely to be in social class IV or $\mathrm{V}$, to live in the most deprived areas and less likely to be ethnically white (all $P<0.001$ ). 'J'- or ' $U$ '-shaped relationships were found between BMI and activities of daily living, respiratory disease, physical activity and mental health variables. In multivariate analysis the fewest significant differences were between the underweight and those of acceptable weight (see Table).

Table. Final model 'underweight' $v$. 'acceptable' weight or 'overweight' participants

\begin{tabular}{|c|c|c|c|c|c|c|}
\hline \multirow[b]{2}{*}{ Variable } & \multicolumn{3}{|c|}{ Underweight $v$. acceptable weight } & \multicolumn{3}{|c|}{ Underweight $v$. overweight } \\
\hline & OR & $95 \% \mathrm{CI}$ & $P$ & OR & $95 \% \mathrm{CI}$ & $P$ \\
\hline Gender: Female & $\mathrm{n} / \mathrm{a}$ & & & 0.30 & $0.14,0.65$ & 0.002 \\
\hline Male & & & & Ref & & \\
\hline Age (years): $\leq 35$ & 2.69 & $1.73,4.19$ & $<0.001$ & 3.30 & $1.84,5.93$ & $<0.001$ \\
\hline $36-55$ & Ref & & & Ref & & \\
\hline $56+$ & 1.23 & $0.67,2.23$ & 0.506 & 1.17 & $0.53,2.62$ & 0.694 \\
\hline Self-reported teeth or mouth problems & 19.4 & $2.66,142$ & 0.003 & $\mathrm{n} / \mathrm{a}$ & & \\
\hline Waist:hip ratio (rescaled) & 0.94 & $0.91,0.96$ & $<0.001$ & 0.81 & $0.77,0.85$ & $<0.001$ \\
\hline Smoking status:Never & $\mathrm{n} / \mathrm{a}$ & & & Ref & & \\
\hline Ex-smoker & & & & 0.84 & $0.40,1.77$ & 0.641 \\
\hline$<10 / d$ & & & & 1.73 & $0.71,4.21$ & 0.225 \\
\hline $10-20 / \mathrm{d}$ & & & & 3.34 & $1.54,7.24$ & 0.002 \\
\hline$>20 / d$ & & & & 3.67 & $1.58,8.53$ & 0.002 \\
\hline Alcohol abstainer & 2.01 & $1.23,3.30$ & 0.005 & 5.72 & $2.84,11.5$ & $<0.001$ \\
\hline Total cholesterol (mmol/l) & $\mathrm{n} / \mathrm{a}$ & & & 0.53 & $0.38,0.74$ & $<0.001$ \\
\hline HDL-cholesterol (mmol/l) & $\mathrm{n} / \mathrm{a}$ & & & 3.24 & $1.69,6.24$ & $<0.001$ \\
\hline
\end{tabular}

n/a, Not applicable; Ref, reference.

Few significant differences were found between the underweight and acceptable-weight groups. No evidence of high levels of physical disease or physical activity was found in the underweight. It could not be concluded that the underweight are less healthy than the other two BMI categories and, therefore, it cannot be recommended that the underweight should be excluded from analyses that examine the effects of obesity on mortality.

1. Flegel KM, Graubard BI, Williamson DF \& Gail MH (2005) JAMA 293, 1861-1867.

2. Willett WC, Hu FB, Colditz GA \& Manson JE (2005) JAMA 294, 551-553.

3. Department of Health (2003) Health Survey for England, 2003. London: The Stationery Office.

4. World Health Organization (1988) Measuring Obesity - Classification and Description of Anthropometric Data. Report no. EUR/ICP/NUT 125-0612v. Copenhagen, Denmark: WHO Regional Office for Europe. 